\title{
Daily Stress Reactivity: The Unique Roles of Personality and Social Support
}

\author{
Aleksandra Kaurin, Aidan G.C. Wright, \& Thomas W. Kamarck \\ University of Pittsburgh, Department of Psychology
}

We wish to thank Dr. Sheldon Cohen for critical comments on a prior draft of this manuscript. Additional online material, the preregistration plan, and the analysis scripts necessary to reproduce our analyses can be retrieved from https://osf.io/28mk6/. The study was funded by the National Institute of Aging (R01 AG041778) The authors declare no conflicts of interest.

Correspondence concerning this article should be addressed to Aleksandra Kaurin, Department of Psychology, University of Pittsburgh, $3^{\text {rd }}$ Floor Sennott Square, 210 S. Bouquet St., Pittsburgh, PA, 15260. E-Mail: kaurinaleksandra@gmail.com 
RUNNING HEAD: PERSONALITY AND SOCIAL SUPPORT IN STRESS REACTIVITY

\begin{abstract}
Background: The processes through which social support exerts its influence in daily
\end{abstract} life are not well understood. Arguably, its salutary effects as an environmental variable might be construed as shared effects of personality. Method: To test this possibility, we investigated the unique and shared effects of personality and social support on daily stressor exposure (social conflict, task strain) and on the within-person association of stressor exposure with perceived stress. A community-sample of $N=391$ adults completed an ambulatory assessment protocol for two 2-day periods with fixed hourly intervals spread across 16 hours. Results: Consistent with our preregistered hypotheses, multilevel structural equation models returned that both, personality and perceived social support, predicted daily stressor exposure and moderated within-person effects of daily stressors on perceived stress. Contrary to our hypotheses, received social support had no effect on daily stress processes. When extraversion, neuroticism, and social support were added as joint predictors, neuroticism and extraversion were related to stressor exposure, and further moderated the within-person link between stressor exposure and stress experience, while perceived social support had an incremental beneficial effect on social conflict exposure and stress appraisal. Conclusion: Social support does not increment the wellestablished relationships between neuroticism or extraversion and stress reactivity.

Keywords: social support, ambulatory assessment, multilevel structural modeling, daily stress reactivity 
RUNNING HEAD: PERSONALITY AND SOCIAL SUPPORT IN STRESS REACTIVITY

The idea that social support shapes individual behavior is rooted in Émile Durkheim's (1897) foundational work on suicides, which, he argued, are more prevalent among individuals with fewer social ties. Interest in the relationship between social support and psychological variables was revived by epidemiological studies in the 1970's and 80's, for instance by Cassel (1976) and Cobb (1976), which proposed that social support serves as a buffer for stress experiences. Ever since, the positive link between social support - generally denoting the presence of caring others - and wellbeing has been demonstrated across a broad range of healthy and ill populations (Cohen, Gottlieb, \& Underwood, 2000; Cohen, Mermelstein, Kamarck, \& Hoberman, 1985; Rueger, Malecki, Pyun, Aycock, \& Coyle, 2016) with studies showing larger effect sizes for several aspects of social relationships than other established risk factors across health outcomes (Holt-Lunstad, Smith, \& Layton, 2010). The specific mechanisms or processes through which social support exerts its influences in daily life, however, are not well understood.

In particular, the unique role of social support effects on health outcomes is clouded by evidence that one's social network likely entails complex associations among individual and contextual variables (e.g., Feeney \& Collins, 2015). Therefore, this study addresses the relative contributions of individual differences in relevant personality traits and social support on daily stress processes using an ecological momentary assessment (EMA) design.

Generally, social support refers to acts of resource provision, that are intended to help an individual (Cohen, 2004). More specifically, it has been defined as interactions that lead someone to "believe that he [SIC] is cared for and loved, esteemed, and a member of a network of mutual obligations" (Cobb, 1976, p. 300). Social support represents a heterogeneous construct (Cohen \& Wills, 1985; Cohen, 2004; Gottlieb \& Bergen, 2010) which can take a variety of forms including belongingness, emotional, esteem, informational, and tangible support (Cohen \& 
RUNNING HEAD: PERSONALITY AND SOCIAL SUPPORT IN STRESS REACTIVITY

Wills, 1985; Wills \& Shinar, 2000). Conceptually, there is a crucial difference between the perceived availability of social support and received support (e.g., Barrera, 1986). Perceived social support describes a relatively stable belief that help will be accessible if needed (e.g., Lakey et al., 2010). Received social support, in contrast, refers to retrospective reports of supportive acts that have actually been received. Although it is generally known that the presence of caring relationships provides coping assistance, particularly at times when the confluence of stressors outweighs individual regulatory abilities (e.g., Cohen, Gottlieb, \& Underwood, 2001), examining both types of support is important. Perceived and received social support are interrelated. However, they represent distinct constructs, which demonstrate differential relationships with mental health or related outcomes and are - at best - only moderately associated with each other (Haber, Cohen, Lucas, \& Baltes, 2007).

Stress is considered to be an important risk factor for a number of health problems (Adler \& Matthews, 1994). The relationship between social support and stress processes has been concisely formalized in Cohen and Wills' (1985) seminal work discussing the stress-buffering effects of social support. The authors proposed two potential mechanisms via which social support may protect individuals against the deleterious effects of stress and maintain or enhance health and well-being in turn. First, social support may affect the way in which individuals appraise stressors that they encounter in daily life (Cassel, 1976; Cobb, 1976; Cohen, 2004). Second, the perceived availability of social support has been hypothesized to moderate the impact of stress on an outcome (Cohen \& Wills, 1985; Kawachi \& Berkman, 2001). Both of these mechanisms are proposed to be important pathways by which social support may be associated with health (Cobb, 1976). 
RUNNING HEAD: PERSONALITY AND SOCIAL SUPPORT IN STRESS REACTIVITY

Empirically, perceptions of supportive relationships (i.e., perceived social support) have been consistently linked to attenuated negative reactions to daily stressors (Eisenberger, Taylor, Gable, Hilmert, \& Lieberman, 2007; Ditzen \& Heinrichs, 2014), have been shown to facilitate emotional recovery from stressors (e.g., Bolger, Zuckerman, Kessler, 2000; Hawkley, Preacher, Cacioppo, 2007), and have been shown to change stress appraisals (e.g., Pietromonaco \& Collins, 2017). Meaningful social connections have also been shown to serve a protective role in reducing neural and physiological responses to pain and stress including heart rate, blood pressure, and neuroendocrine responses (Montoya et al., 2004; Ozbay et al., 2007).

In contrast to perceived social support, received support has not been consistently positively linked to mental health (e.g., Finch, Okun, Pool, \& Ruehlman, 1999). In some cases, received support has even been linked to poorer, instead of better mental health outcomes (Bolger \& Amarel, 2007; Bolger, Zuckerman, \& Kessler, 2000; Gleason, Iida, Shrout, \& Bolger, 2008). Related work suggests that support receipt may create feelings of obligation, threaten selfesteem and the sense of self-efficacy, or evoke guilt, accounting for its deleterious impact (Bolger \& Amarel, 2007; Gleason, Iida, Bolger, \& Shrout, 2003).

Lakey \& Orehek (2011; see also Cohen \& Wills, 1985) suggest that the association between received social support and stress could be accounted for by the fact that individuals who experience generally higher levels of stress also tend to generally receive higher amounts of support, while also reporting worse mental health. More specifically, the authors put forward that previous work has not sufficiently ruled out the possibility that main effects of social support reflect recipient personality. Thus, interpretations of whether research findings reflect personality or social processes primarily reflect the fact that social support may be viewed as a construct that is either influenced by or shares substantial overlap with personality (Lakey \& Drew, 1997; 
RUNNING HEAD: PERSONALITY AND SOCIAL SUPPORT IN STRESS REACTIVITY

Lakey, McCabe, Fisicaro, \& Drew, 1996; Lutz \& Lakey, 2001; Swickert, Rosentreter, Hittner, \& Mushrush, 2002; Swickert \& Owens, 2010; see also Bergeman, Plomin, Pedersen, McClearn, \& Nesselroade (1990) for potential genetic influences on social support). Seeming benefits of social support could, therefore, actually reflect individuals' levels of basic traits, like extraversion or neuroticism and consequences of reactive, evocative, or proactive processes between individual differences and one's supportive social environment (e.g., Pierce, Lakey, Sarason, Sarason, \& Joseph, 1997).

Individual differences may affect both exposure to as well as the response to stress (Liu \& Alloy, 2010). For instance, neuroticism, often denoted as emotional instability, has been linked to the probability of experiencing distress, the evaluation of an event as taxing, the likelihood of enacting certain coping strategies, and the success of these coping strategies (Grant \& Langan-Fox, 2007; Penley \& Tomaka, 2002; Suls \& Martin, 2005). Moreover, neuroticism might adversely affect the quality of social relationships and increase the probability of exposure to interpersonal stress (Branje, van Lieshout, van Aken, 2004; David \& Suls, 1999; Hooker, Frazier, \& Monahan, 1994; Lara, Leader, \& Klein, 1997; Suls \& Martin 2005). Neuroticism has also been linked to lower levels of perceived social support (Ayub, 2015; Branje et al., 2004; Swickert et al., 2010). Findings from daily diary studies provide further evidence for the link between neuroticism and the experience of more (interpersonal) stress, elevated levels of stress intensity and reactivity (Bolger \& Schilling, 1991; Howland, Armeli, Feinn, \& Tennen, 2017; Mroczek \& Almeida, 2004; Suls et al., 1998), as well as the habitual use of poorer coping strategies in response to everyday stress. Neuroticism may facilitate the maintenance of current stressors or the generation of future ones (Gunthert, Cohen \& Armeli, 1999). Thus, individuals who score high on neuroticism may report more daily stressors and - in turn - higher levels of 
RUNNING HEAD: PERSONALITY AND SOCIAL SUPPORT IN STRESS REACTIVITY

perceived stress, because of less perceived social support, or because they are quicker to appraise a situation as stressful (Bolger \& Zuckerman, 1995).

Extraversion, in contrast, relates to perceiving events as challenges rather than threats and to positive appraisals of coping resources (Longua, DeHart, Tennen, \& Armeli, 2009; Penley \& Tomaka, 2002; Vollrath, 2001). Also, as individuals high in extraversion are characterized by sociability, it is likely that they will enjoy wider social networks and seek out more social support than those lower in extraversion (e.g., Ashton, Lee, \& Paunonen, 2002; Feiler \& Kleinbaum, 2015; Morelli, Leong, Carlson, Kullar, \& Zaki, 2017; Morelli, Ong, Makati, Jackson, \& Zaki, 2017; Williams, Morelli, Ong, Zaki, 2018; see Baranczuk (2019) for a metaanalysis). In daily diary studies, high levels of extraversion have been linked to fewer instances of stress exposure, lower stress-reactivity, and positive appraisals of available coping resources (Gunthert, Cohen, \& Armeli, 1999; Suls \& Martin, 2005). A study based on a community sample of men found that those with relatively high levels of extraversion tended to engage more frequently in emotion-focused coping strategies (e.g., venting of affect in response to daily stressors; David \& Suls, 1999). This overall pattern was mirrored by the additional observation that more extraverted participants exhibited a tendency to engage their social networks in response to daily stressors. A similar ambulatory assessment study in a sample of individuals with Rheumatoid Arthritis - a condition associated with a multitude of daily stressors complements this set of findings by showing that individuals high in extraversion were more likely to use adaptive coping strategies such as cognitive reframing in response to a daily stressor and they were more likely to benefit from engaging in those strategies as well (Newth \& DeLongis, 2004). 
RUNNING HEAD: PERSONALITY AND SOCIAL SUPPORT IN STRESS REACTIVITY

Potentially, the daily stress-buffering effects of drawing support from one's broader social network can be accounted for by perceived and received social support, over and above personality. Research on social support univocally suggests that those who perceive themselves as having social support find negative events to be less aversive than those who perceive that they have little or no support. For instance, in daily diary and longitudinal exploratory studies, the within-person link between daily stressors and affect was stronger for people who perceived themselves as having less social support (Caspi, Bolger, and Eckenrode, 1987; DeLongis, Folkman, Lazarus, 1988; Nezlek \& Allen, 2006). More specifically, Affleck, Tennen, Urrows, and Higgins (1994) found that social support moderated one-day lagged relationships between negative events and negative mood but not same-day relationships. The lagged relationship was greater for people with less social support than for those with more support. This finding resembles work by DeLongis, Folkman, and Lazarus (1988) suggesting that within-person sameday relationships between mood and daily hassles are stronger for people who had less social support than for those who had more support.

Global perceptions of support availability, as well as perceptions of support attempts from close others, may be associated with the frequency of specific coping strategies, the effectiveness of strategies employed (e.g., DeLongis \& Holtzman, 2005; Heller, Swindle, \& Dusenbury, 1986), as well as health-related outcomes more generally (Bisconti, Bergeman, \& Boker, 2006; Cook, McElwain, \& Bradley-Springer, 2016; Gerteis \& Schwerdtfeger, 2016).

The Present Study. What is not entirely clear from existing research is whether individual differences in personality relevant to social support, such as neuroticism and extraversion, confer shared or unique effects in moderating within-person relationships between daily events and stress appraisals. Because of the links between both perceived and received 
RUNNING HEAD: PERSONALITY AND SOCIAL SUPPORT IN STRESS REACTIVITY

social support with coping processes, the putative salutary effects of support as an environmental variable might be construed as effects of individual differences in contextualized personality processes. This study seeks to disentangle the effects of recipient traits from perceived and received social support, thus clarifying the unique and shared salutary effects of personality and social support on daily stress processes. Our study uses an ecological momentary assessment (EMA) study design, with intensive and repeated assessments of stress appraisals in an individual's natural environment (Moskowitz et al., 2009; Trull \& Ebner-Priemer, 2013; Wright et al., 2019). There are three major methodological advantages specific to EMA designs. First, collecting data in natural settings permits the examination of socio-affective processes as they unfold in real-world contexts. This maximizes ecological validity and generalizability that are limited in laboratory settings. Second, momentary measures have been shown to reduce bias and systematic error associated with traditional retrospective self-reports (Trull \& Ebner-Priemer, 2013). Third, the use of repeated assessments throughout the day allows us to capture withinperson variability with a temporal resolution that is not possible with alternative approaches. Repeated assessments provide representative samples of everyday stressor exposure along with episodic psychological responses that may accompany those events. In that regard, EMA represents a unique approach toward harmonizing assessments of stress exposure and susceptibility because it allows us to capture both constructs in a way that closely aligns with our daily life experience. In sum, EMA permits to reliably model the dynamic interplay of environmental triggers on stress processes as they unfold in real-world contexts.

Stress processes are ideal for studying the joint and distinctive impact of perceived and received social support and personality on the contextualized processes that may underlie individual differences in health and wellbeing (e.g., Wright, Aslinger, Bellamy, Edershile, \& 
RUNNING HEAD: PERSONALITY AND SOCIAL SUPPORT IN STRESS REACTIVITY

Woods, 2019). Especially interpersonal conflicts have been found to have strong negative effects on psychological well-being (Bolger, DeLongis, Kessler, \& Schilling, 1989; Rook, 1992), and to activate stress physiology (Kiecolt-Glaser \& Newton, 2001).

Conventionally, stress is defined as a transactional process arising from existing or perceived environmental demands that can be appraised as threatening or benevolent, depending on the availability of coping resources to an individual (e.g., Lazarus \& Folkman, 1984). As outlined above, personality traits and social support both can influence any point of a coping sequence such as exposure or response to stressors, as well as their within-person links across time. Thus, stressful experiences during daily life that may evoke different responses as a function of individual differences and/or social support are likely to be an important process operating in health and wellbeing.

For this study, two types of events — social conflict and task strain — were selected as key determinants of daily stress reactivity on the basis of their hypothesized associations stressinduced sympathetic nervous-system responding (Manuck et al., 1991; Schnall et al., 1992).

The main objective of this study was to determine whether and how basic personality traits (i.e., extraversion, neuroticism) and perceived or received forms of social support uniquely relate to processes of perceived stress exposure and reactivity in daily life. As preregistered, we hypothesized that social support and personality will have unique effects on (i) stressor exposure, and (ii) the within-person link between stressor exposure and perceived stress (see Figure 1 for effect annotations).

\section{Hypotheses}


RUNNING HEAD: PERSONALITY AND SOCIAL SUPPORT IN STRESS REACTIVITY

Perceived Stress Exposure. The first set of hypotheses examined the between-person portion of our model, concerning effects of personality and social support on individual differences in perceived stress.

Hypothesis 1a: Individual differences in perceived and received social support will be negatively associated with ratings of daily life stressor occurrence and intensity (task demand and social conflict) during daily life.

Hypothesis $1 b$ : Levels of extraversion will be negatively, while levels of neuroticism will be positively, associated with ratings of daily life stressor occurrence and intensity Hypothesis 1c: When entering social support and personality variables simultaneously in one model, all variables will uniquely contribute to daily life ratings of stressor occurrence and intensity.

Amplified Stress Response. The second set of our preregistered hypotheses focused on the moderating effects of personality and social support on the within-person association between momentary stressors and perceived stress in daily life.

Hypothesis 2a: Low levels of perceived and received social support will amplify the withinperson association between reports of daily stressor and perceived stress. Hypothesis 2b: Both high levels of extraversion and neuroticism will amplify the withinperson association between reported daily stressors and perceived stress. Hypothesis 2c: When entering all variables in one model, each of these four predictors will uniquely amplify the within-person association between reported daily stressors and perceived stress.

To further control for the possibility of suppression effects, extraversion and neuroticism will be first entered as predictors in separate models, before merging them into one 
RUNNING HEAD: PERSONALITY AND SOCIAL SUPPORT IN STRESS REACTIVITY

comprehensive model. The concept of a suppressor variable describes cases in which the inclusion of a second predictor increases the predictive power of the first predictor by controlling for criterion-irrelevant variance (Lynam, Hoyle, \& Newman, 2006; Paulhus et al., 2004), potentially revealing patterns of stress-specific and nonspecific components that likely operate in tension with one another.

In a parallel set of analyses, we also operationalized momentary perceived stress as momentary negative affect. This led to very similar patterns of results.

The output of all supplementary analyses can be found on the OSF (Tables S1-S7).

\section{Method}

\section{Open Practices}

All code and model output are available on the OSF (https://osf.io/28mk6/). The design and analysis plans for this study were preregistered at the OSF (https://osf.io/74u36). Our consent form did not request permission for open sharing of the data, and therefore we are unable to post the data online.

\section{Procedures}

All study procedures were approved by the University of Pittsburgh Institutional Review Board (PRO13010074), and all participants were administered informed consent before enrollment.

Potential subjects for SHINE (Study of Health and Interactions in the Natural Environment) were recruited by the University Center for Social and Urban Research (UCSUR) at the University of Pittsburgh, using targeted telephone recruitment methods. A telephone interviewer contacted all respondents for purposes of study description and initial screening for eligibility. If interested and eligible, the potential participant was scheduled for a study visit. 
Eligible participants were middle aged (age 40-64) and in generally good health. Exclusion criteria were based upon an effort to reduce major confounding medical and health-related variables that might influence the measures of affect, health behavior, and cardiovascular, metabolic, and inflammatory processes that were the focus of the study. Thus, individuals who reported chronic illness, diabetes requiring medication, or recent cancer requiring treatment were excluded, as were those with untreated high blood pressure (SBP $>180$ or DBP $>110)$, or neurological deficit. Furthermore, those taking psychotropic medications, or medications with autonomic, HPA axis, inflammatory, or metabolic effects were excluded. Moreover, participants were excluded if they reported health habit or life situations that may adversely affect participation. These include excessive alcohol consumption ( $>5$ drinks $>3$ times per week), recent recreational drug use, current shift work, current pregnancy, or less than an $8^{\text {th }}$ grade education. Subjects attended 4 laboratory visits: an informed consent and screening visit, a social network assessment visit, an ambulatory monitoring training visit, and a debriefing visit. Primary data collection occurred over the course of a 4-day period, between visits 3 and 4 . Throughout this period, electronic diary (ED) monitoring assessments were carried out, along with hourly ambulatory blood pressure assessments and measures of salivary cortisol, collected six times daily (data not relevant to this current report). During Visit 1, informed consent was administered, followed by demographic and social network assessment. Visit $3^{1}$, usually on Monday, was devoted to training in ambulatory monitoring. Each subject was required to meet demonstrated competence on use of equipment before being sent into the field for a

\footnotetext{
1 Training sessions began with a self-paced tutorial developed as part of our previous research. Each subject was required to meet demonstrated competence on use of equipment the "shakedown" trial.
} 
"shakedown" trial. Following brief telephone contact to troubleshoot any technical or operational difficulties, ambulatory data collection began the next day (typically Tuesday) ${ }^{2}$.

For the duration of their ambulatory monitoring session - two two-day periods over the course of one week -, participants were given a mobile phone (Nexus S) equipped with programmed software previously designed to facilitate EMA assessment. Subjects were instructed to use the ED throughout each monitoring day (approximately $16 \mathrm{hrs}^{3}$ ) and they completed questions administered by the ED at fixed hourly intervals ${ }^{4}$. Right before bedtime, participants were prompted to complete an evening interview, to turn off the device, and to set a set a wake-up alarm on the ED for the time of their choosing for the following morning. Upon awakening, participants were asked to activate the device and to complete a morning interview. Hourly interviews were prompted by the inflation of the ambulatory blood pressure device, donned within 45 minutes of awakening. Additional physiological assessments were collected during the monitoring period (cortisol and urinary catecholamines), but these were not relevant to the analyses reported here. Participants were encouraged to respond immediately following each prompt, but they were allowed to 'delay' responding, if necessary, if circumstances were prohibitive (e.g., meeting or phone call). Responses that were completed 22 minutes or greater following each cuff inflation were deemed invalid and were deleted.

\footnotetext{
${ }^{2}$ To minimize any annoyance and/or frustration that may result from interacting with the electronic diary devices, all subjects were appropriately trained on how to use the devices prior to being sent out into the field. Furthermore, during the entire monitoring period while subjects were in the field, a research specialist was ready and available (by cell phone) to answer any questions.

${ }^{3}$ After an initial morning interview, participants were given an hour to shower and to don their equipment, resulting in a maximum of 15 possible interviews per day (or 60 possible prompts over the course of the 4-day study, respectively).

${ }^{4}$ The present study drew data from a larger parent project, designed, in part, to explore the link between psychosocial factors and acute cardiovascular responsiveness in daily life. In the context of the overarching goal of the parent study, ambulatory diary measures of stressor exposure and adaptive reactivity were set to be synchronized with hourly cuff inflations of ambulatory blood pressure. More specifically, blood pressure was assessed every 60 minutes throughout the day (which corresponded to approximately 16 waking hours per participant). Immediately following each blood pressure measurement, participants were prompted to complete a 2-minute electronic diary. This protocol has been applied in a number of previous studies (Kamarck et al., 2018), and has been proven useful for the examination of episodic adjustments in hemodynamic activity that may accompany ongoing stressor events.
} 
RUNNING HEAD: PERSONALITY AND SOCIAL SUPPORT IN STRESS REACTIVITY

At the end of the data collection period, subjects attended a morning lab visit (Visit 4), for data download, to return their equipment, to complete a blood draw, to complete additional questionnaires, to facilitate subject payment ( $\$ 350$ for completion) and to discuss the study ${ }^{5}$.

\section{Sample}

391 participants completed ambulatory assessment procedures. Due to errors in the software used to administer questionnaires, 11 of these were missing social support data and 21 were missing personality data. Other than noted in our preregistration, this yielded a sample size of 370 with complete data available for hypotheses involving the cross-level interaction between momentary and trait measures. $61.4 \%$ of the sample was female $(N=240)$, and $22.5 \%$ was nonwhite, with a mean age of 52 years. The sample was generally well educated ( $64 \%$ with bachelor's or graduate degree). At the within-person level, this returned $N=11275$ momentary observations of social stressors, and $N=19165$ momentary observations of task-related stressors, with an average compliance rate of $71 \%$.

Fewer observation numbers for social conflict compared to task demand result from our effort for the social conflict variable to extract only responses pertaining to interactions reported to be occurring at the time of or within the 10-minute period preceding the ED assessment. An average of $N=30$ ambulatory monitoring observations (i.e., diary entries) per person were available for analyses based on social stressors, and $N=52$ for analyses based on task-related stressors.

\section{Assessment of Personality and Social Support}

Psychometric details for all scales can be found in Table 1. Personality traits were measured with the NEO Five-Factor Inventory (Costa \& McCrae, 2008).

\footnotetext{
${ }^{5}$ Based upon their adherence to study procedures, 25 subjects agreed to undertake 1-3 days of additional data collection in order to remain eligible to complete the study.
} 
RUNNING HEAD: PERSONALITY AND SOCIAL SUPPORT IN STRESS REACTIVITY

Perceived Social Support was assessed with the short form of the Interpersonal Support Evaluation List (ISEL-12; Cohen, Mermelstein, Kamarck, \& Hoberman, 1985). 12 items assess the perceived availability of social support on a four-point scale ranging from "definitely false" to "definitely true." All items are summed to yield a total score (scores range 0-36) or four items per subscale. The tangible subscale measures the perceived availability of material aid, the appraisal subscale the perceived availability of someone to talk to about one's problems and the belonging subscale the perceived availability of people one can seek companionship with.

Received Social Support was assessed using the Positive Social Exchanges subscale of the Positive and Negative Social Exchanges (PANSE; Newsom et al., 2003) scale. Twelve items assess the frequency with which positive social exchanges have occurred within the past month within the following domains (three items per domain): emotional support, companionship, instrumental support, and informational support.

\section{Assessment of Momentary Stress Processes}

Variables measured in EMA surveys were derived from a self-reported multi-item electronic diary assessment tool, used for repeated real-time assessments. Participants completed the diary on an hourly basis. The diary includes scales assessing current affect and stressor exposures, including measures of task demand and social conflict. For each of the items, participants respond using a 10-point scale (with the anchors NO! No no yes Yes YES!). As preregistered, due to an error in our assessment software (inability to reliably detect the full range of the scale), response options for each item were transformed to range from 1 to 9 .

To assess task/work-related stressors, participants were asked to "Think about mental and physical activity in the past 10 minutes." The three-item task-demand scale (i.e., "Required working hard?" "Required working fast?" and "Juggling several tasks at once?") followed. These 
RUNNING HEAD: PERSONALITY AND SOCIAL SUPPORT IN STRESS REACTIVITY

items were derived from the Job Content Questionnaire (Karasek et al., 1985), a standard instrument used for the assessment of job strain. Retest reliability and criterion validity for this EMA-based scale has been previously described (Kamarck, Muldoon, Shiffman, Sutton-Tyrrell, Gwaltney, 2004). During each hourly assessment, participants were also administered several items inquiring about their most recent social interaction. Social conflict scores for these recent interactions were assessed using a three-item scale (i.e., "Someone was insensitive to you?" “Someone made you tense?" "Someone interfered with your efforts?”; e.g. Kamarck et al., 2018). For both types of stressors, scores were averaged across items for each scale. Betweenand within-person reliabilities were calculated for these scales using McDonald's omega ( $\omega$; Zinbarg, Revelle, Yovel, \& Li, 2005).

Momentary perceived stress was assessed with one item: "How feeling? Nervous / Stressed?" Average reliability coefficients are depicted in Table 1.

\section{Focal Preregistered Analyses}

We used Mplus Version 8.3 (2019) to estimate multi-level structural equation models (MSEMs). A simplified overview of tested paths can be found in Figure 1. Total variance in the observed variables of stressors and stress response was broken down into within- and betweenperson latent variables using latent decomposition. This is analogous to the partitioning of variance that occurs with the outcome variable in standard multilevel modeling, however in MSEM it is conducted for both outcomes and predictors that are observed at Level 1 (i.e., variables that have both within and between-person variance). The between-person variables (i.e., Level 2) are an estimate of an individual's average (i.e., random intercepts), and the withinperson variables (i.e., Level 1) reflect deviations from their average during a given repeated assessment. Because all the modeled associations are among concurrently assessed variables and 
RUNNING HEAD: PERSONALITY AND SOCIAL SUPPORT IN STRESS REACTIVITY

not lagged, this means that the within-person associations reflect situation-to-situation dynamic processes, but they do not directly establish temporal precedence.

We used the Bayes estimator. No prior information about parameter values was specified (i.e., we used non-informative/diffuse priors that are the default in Mplus). Inferences were based on point estimates drawn from their posterior distribution and associated $95 \%$ credibility intervals. We considered coefficients in which the credibility interval did not include zero to be significantly different from the null hypothesis.

To test our first set of hypotheses, we examined whether dispositional measures of personality and perceived or received social support predicted individual differences in random intercepts of task-related and social stressors. For analyses based on the second set of our hypotheses, we examined whether individual differences in personality and social support moderated the within-person association between reported daily stressors and perceived stress (i.e., cross-level interaction). For tests of hypotheses $1 \mathrm{a} / \mathrm{b}$ and $2 \mathrm{a} / \mathrm{b}$, extraversion, neuroticism and social support were entered as separate predictors to the model, whereas for tests of hypotheses $\backslash$ $1 \mathrm{c}$ and $2 \mathrm{c}$, all three sets of predictors were joined into one model.

In accordance with previous analyses based on this or similar datasets (Kamarck et al., 2004; Kamarck et al., 2018), we used age, gender, race, and education as covariates at the between-person level in all analyses. Race was coded using a dichotomous scale (white/nonwhite) and education was designated with a 4-point scale (high school, some college or associates, BA/BS, post-BA degree). Covariates were modeled only at the between-person level. To control for the effects of each, random slopes and intercepts were regressed on covariates. Preregistered syntaxes of our analyses can be found on the OSF.

\section{Supplementary Analyses}


RUNNING HEAD: PERSONALITY AND SOCIAL SUPPORT IN STRESS REACTIVITY

To harness the full potential of the dataset, we further carried out a series of supplementary analyses, all of which can be found at the OSF (https://osf.io/28mk6/): In our models, perceived and received social support were conceptualized as broad overarching constructs. However, because social support is a heterogeneous construct (Cohen \& Wills, 1985; Gottlieb \& Bergen, 2010) its distinct elements may be obscured by the use of an overall score. Therefore, we also pre-registered exploratory analyses examining the moderating role of social support on stress reactivity based on each of the available subscales of perceived and received social support (see below for a detailed overview of subscales). The results of those analyses can be found on the OSF (Table S8-S10), and will be presented in the context of the broader discussion of this article.

Finally, for both sets of hypotheses, further exploratory analyses were carried out, examining the contribution of agreeableness, conscientiousness, and openness to the probability of individuals reporting a stressor in daily life and the efficacy of self-regulatory success after experiencing stress in daily life (OSF: Tables S11-S12).

\section{Results}

\section{Preliminary Analysis}

To validate our momentary models of stress reactivity, we regressed ratings of momentary perceived stress on each of the stressor perception domains separately at Level 1 (see lower part of Figure 1) and at Level 2. Individual differences in stressor exposure and perceived stress were allowed to freely correlate (see upper part of Figure 1). These baseline model analyses were described in our preregistration and outputs for all reported models can be found on the OSF (https://osf.io/74u36). 
RUNNING HEAD: PERSONALITY AND SOCIAL SUPPORT IN STRESS REACTIVITY

Our analysis returned a significant effect of task demand at the within-person level $(\beta=.23, \mathrm{CI}=.18 ; .26)$ and at the between-person level $(\beta=.39, \mathrm{CI}=.28, .48)$. The results for models including social conflict as predictor variable were $\beta=.31(\mathrm{CI}=.29 ; .34)$ at the withinand $\beta=.65,(\mathrm{CI}=.59 ; .71)$ at the between-person level, respectively. This pattern of associations and variability supports the validity of our measures' ability to reflect momentary stress elevation in response to work- and interpersonally related stressors.

An overview of zero-order correlation coefficients can be found at the OSF (https://osf.io/74u36; Table S14).

\section{Perceived Stress Exposure}

All analyses were carried out in the context of the four demographic covariates specified above and the detailed output is available at the OSF.

Table 2 summarizes coefficients related to hypotheses $1 \mathrm{a}$ and $\mathrm{b}$. To test the effect of social support (H1a) and personality traits (H1b) on the probability of experiencing a stressor in daily life, we ran separate simple prediction models. These models returned significant positive effects of extraversion on the amount of reported work-related stressors $(\beta=.09$, CI: .01; .16), and significant positive effects of neuroticism $(\beta=.23, \mathrm{CI} . .16 ; .31)$ and negative effects of perceived social support ( $\beta=-.16, \mathrm{CI}:-.23 ;-.08)$ on social conflict exposure. Received social support, in contrast to our prediction (H1a), had no effect on the perceived exposure to stressors.

Table 3 summarizes coefficients related to hypothesis 1c. Assessing the shared and unique predictive validity of each variable in a combined prediction model elucidated that neuroticism $(\beta=.12, \mathrm{CI}: .05 ; .20)$ and extraversion $(\beta=.11, \mathrm{CI}: .03 ; .18)$ incrementally added to the explanation of variance in task demand, while neuroticism $(\beta=.20, \mathrm{CI}: .12 ; .26)$ and perceived social support ( $\beta=-.10, \mathrm{CI}:-.18 ;-.02)$ incrementally added to the explanation of 
RUNNING HEAD: PERSONALITY AND SOCIAL SUPPORT IN STRESS REACTIVITY

variance of social conflicts to emerge in daily life. Except for extraversion, each of these variables was associated in the preregistered direction across stressor domains.

\section{Amplified stress reactivity}

In the context of hypotheses $2 \mathrm{a}$ and $\mathrm{b}$, we tested the moderating value of dispositional measures on within-person associations between reported daily stressors and perceived stress (i.e., cross-level interaction). Coefficients emerging from the " $\rightarrow$ Reactivity" path of our models in Table 2 reflect key estimates for those hypotheses (and in Table 3 for Hypothesis 2c, respectively).

In line with hypothesis $2 \mathrm{a}$, we found that perceived social support dampened the link between daily social conflicts or task demand and perceived stress ( $\beta=-.13, \mathrm{CI}$ : -.20; -.04). Received social support, however, had no effect on stress reactivity. In line with hypothesis $2 b$, neuroticism enhanced the link between both types of daily stressors and perceived stress $(\beta=.19$, CI: .09;.27; $\beta=.12$, CI: .02; .20), while the predicted effect for extraversion did not emerge.

Hypothesis $2 \mathrm{c}$ predicted that personality and social support would uniquely amplify the within-person association between reported daily stressors and perceived stress. In contrast to our hypothesis, when entering all predictors concurrently into one model, only neuroticism emerged as significant moderator of stress reactivity, and only so in the context of daily workrelated stressors $(\beta=.18, \mathrm{CI}: .07 ; .28$; Table 3$)$.

\section{Discussion}

A seldom-tested explanation for the effectiveness of perceived social support in ameliorating the detrimental effects of stress is that it may be attributable to relevant personality characteristics. In this preregistered study, we tested the extent to which daily stress-buffering effects of drawing support from one's broader social network can be accounted for by perceived 
RUNNING HEAD: PERSONALITY AND SOCIAL SUPPORT IN STRESS REACTIVITY

and received social support, over and above neuroticism and extraversion, two traits that share substantial overlap with processes of social support. Our study illustrates that perceived social support has a protective effect on the probability of experiencing a stressor in daily life (Hypothesis 1a), even after controlling for traits that are closely related to social support (Hypothesis 1c). Neuroticism (Hypothesis 1b) was related to an increased level of overall stressor exposure, and extraversion to more frequent reports of work-related stressors. As expected, perceived social support (Hypothesis 2a) and personality (Hypothesis 2a) moderated relationships between stressor exposure and experienced stress. In contrast to our hypotheses, the ability of perceived social support to buffer reactivity to stressful experiences, however, disappeared after controlling for personality (Hypothesis 2c). Received social support neither had an effect on stressor exposure (Hypothesis 1a), nor stress reactivity (Hypothesis 2a).

Overall, our results are in line with previous work suggesting that personality, and neuroticism in particular, reflects greater reactivity of negative affect to unpleasant events and stressors (Bolger \& Schilling, 1991; Longua, DeHart, Tennen, \& Armeli, 2009; Maples, Miller, Hoffman, \& Johnson, 2014). To some degree, this overall picture contrasts with previous work by Cohen et al. (2015), reporting that perceptions of social support and the frequency of being hugged or experiencing interpersonal tension were not influenced by relevant personality characteristics (i.e., extraversion, agreeableness, and neuroticism), although all traits that have been associated with social interaction styles. It is possible that our findings deviate from those reported in Cohen et al. (2015) because the outcomes were differentially indicative of social support and personality across both studies. As Cohen et al. (2015) put forward, hugging may represent a behavioral indicator of social support, whereas the main outcome in our study (i.e., the within-person link between stressor and stress response) could be viewed to reflect the 
RUNNING HEAD: PERSONALITY AND SOCIAL SUPPORT IN STRESS REACTIVITY

momentary regulation of trait indicative behavior (Fleeson, 2012; Wright, 2011, 2014), thus

diminishing the predictive validity of perceived social support after controlling for neuroticism or extraversion.

Alternatively, it is also possible that, even though social support may be mobilized instantaneously, the positive effects of such support are likely experienced with some temporal distance. Thus, although supportive relationships may not guard against the immediate adverse effects of stressful daily events, they may guard against negative long-term health effects of daily stress experiences (Caspi et al., 1987).

Partially aligning with this explanation are findings regarding our first set of hypotheses. Although the pattern of our results replicates previous evidence illustrating that neuroticism increases the probability of exposure to stressors - and levels of perceived stress in turn - more generally (e.g., Suls \& Martin, 2005), it also adds to this well-established relationship. The incremental effect of perceived social support on the likelihood of reporting an interpersonal stressor in daily life may potentially mirror the notion that the occurrence of stressful events likely propel individuals with highly supportive social networks into positive social encounters, and thus decrease the probability of detrimental health effects in the long run (e.g., Caspi et al., 1987; Cutrona, 1986; Nezlek \& Allen, 2006).

The findings presented here are based on a design with a notable ability to approximate real-world daily stress processes: We assessed stress reactivity of individuals hourly in their daily lives across two two-day periods over the course of a week (i.e., 4 days total) in a community sample, combining the twin benefits of increased ecological validity and minimized retrospective biases. Although the general picture emerging from this set of analyses is that the seeming benefits of social support on daily stress reactivity could be viewed as reflections of 
RUNNING HEAD: PERSONALITY AND SOCIAL SUPPORT IN STRESS REACTIVITY

individuals' basic trait levels and consequences thereof (e.g., Pierce et al., 1997), some aspects deserve further discussion.

It is important to note that our sample was relatively well-educated and predominantly white which may limit the generalizability of our results to other groups.

Moreover, because EMA encompasses a methodological approach that is characterized by complex sampling procedures and data analytic choices, each individual study's specifics may introduce a new source of variance or capture different aspects of the hypothesized processes. Thus, this circumstance may complicate the comparability of results across seemingly very similar studies. To illustrate, a recently published study found no evidence for neuroticism moderating the within-person link between negative affect and daily stressors (Mey et al., 2020). This contradicts the the findings reported in our study, as well as the majority of studies revealing an impact of neuroticism on stress reactivity following daily hassles (e.g., Bolger \& Schilling, 1991; Marco \& Suls, 1993; Mroczek \& Almeida, 2004; Suls et al., 1998). However, Mey et al. (2020) used a small sample $(N=70)$, employed a brief measure of affect valence with two uncommonly used items (i.e., discontent, unwell), and had relatively long temporal periods covered by each prompt. Thus, it is possible that any number of these choices could have impacted their findings. Future studies should, therefore, systematically evaluate alternative methodological decisions including selection of affect items and timing of assessments.

Because it can be argued that self-reported measures of social support and personality reflect a blend of social and intraindividual differences (e.g., Lakey \& Orehek, 2011), we ran a supplementary set of analyses to control for the possibility of plausible suppression effects. A detailed overview of results from these models can be found in [supplementary Table S13]. In those models, extraversion and neuroticism were first entered as predictors in separate models 
RUNNING HEAD: PERSONALITY AND SOCIAL SUPPORT IN STRESS REACTIVITY

(see Table 2), before merging them into one comprehensive model with measures of social support (Table S13). While extraversion was not predictive of stress reactivity in the context of social conflicts per se, a moderating effect of social conflict reactivity arose when we controlled for perceived and received social support. This suggests that adjusting for social support variables may reveal the predictive power of extraversion, by bringing into clearer focus elements that are inherent — but largely hidden — in the overall score of extraversion (e.g., Watson, Clark, Chmielewski, \& Kotov, 2013).

The idea of overlapping variance in constructs of interest is also relevant for study design considerations that aim at the disentanglement of effects emerging from the support recipients' traits vs. effects that stem from interpersonal influences. The fact that all measures in our study were assessed via self-report may hamper the ability of our design to sufficiently distinguish between these effects in daily life, because a correlation between a self-reported measure of perceived support and stress processes likely reflects large amounts of the traits themselves. If respondents make judgments of their social ties, by guessing average supportiveness across different providers, then, according to reliability theory (Cronbach et al., 1972), general measures of perceived support compound recipient trait variance by averaging out effects due to providers (Lakey \& Orehek, 2011). As Lakey \& Orehek (2011) suggest, future studies should, therefore, ask respondents to rate a single, most important support provider. That way the magnitude of recipient influences is not overestimated by averaging across multiple providers and the magnitude of the confound is reasonably low. Alternatively, future work may also employ informant reports of social support and test the effects reported in our study systematically across a variety of different, yet related outcomes (e.g., health behaviors, physiological processes). 
RUNNING HEAD: PERSONALITY AND SOCIAL SUPPORT IN STRESS REACTIVITY

To more specifically tackle the question of determinants of perceived benefits of social support, future studies may also consider assessing interactive effects of personality and social support on momentary stress processes. Because interaction effects require large sample sizes (e.g., Rohrer \& Arslan, 2020) and thoughtful consideration of the strength and form of the effects, we suggest basing related analyses on carefully planned and (ideally) preregistered study protocols, thus reducing potential threats to reliability and preventing the introduction of falsepositives into the literature.

Moreover, future work may also employ high-resolution studies with more in-depth measurements of social support. This notion is built on more recent evidence, suggesting that the conceptualization of social support as a static construct may conceal relevant features of social support (Coppersmith et al., 2019). Capturing social support with a single assessment does not take into account the volatile nature of perceived social support, which is known to fluctuate even over short periods of time and relatively restricted scales.

Although aspects of method variance are key for future studies to carefully parse out redundant variance between social support measures and those of closely related personality variables, it may also be that an incremental effect of social support on daily stress processes may be very small. Thus, it would require very large samples to detect it. Indeed, the effect of neuroticism was large, making the detection of additional, likely smaller effects, more difficult to emerge.

Our research points towards the crucial role of one's supportive social environment to increment effects of personality on daily stress processes. However, follow-up studies using a more extensive longitudinal design across different methods, and a broader range of outcomes are needed to corroborate our findings. Possibly, to the extent that an unhappy or sunny 
RUNNING HEAD: PERSONALITY AND SOCIAL SUPPORT IN STRESS REACTIVITY

disposition itself affects a person's location in the social structure, correlations between social support and daily stress processes could reflect the effects, not the causes of stress regulation. Therefore, not the provision of social support per se, but understanding personality profiles associated with successful social relationships may aid in increasing social connectedness and lower stress experience in the long run. This process needs careful study, combining daily indicators of social interaction with measures of daily events and well-being. Our findings provide limited evidence of incremental effects of social support and personality, yet a mechanistic account that accommodates these nuanced results beckons further study. 
RUNNING HEAD: PERSONALITY AND SOCIAL SUPPORT IN STRESS REACTIVITY

\section{References}

Affleck, G., Tennen, H., Urrows, S., \& Higgins, P. (1994). Person and contextual features of daily stress reactivity: individual differences in relations of undesirable daily events with mood disturbance and chronic pain intensity. Journal of Personality and Social Psychology, 66(2), 329-340. doi:10.1037/0022-3514.66.2.329

Ashton, M. C., Lee, K., \& Paunonen, S. V. (2002). What is the central feature of extraversion? Social attention versus reward sensitivity. Journal of Personality and Social Psychology, 83(1), 245-252. https://doi.org/10.1037/0022-3514.83.1.245

Barańczuk, U. (2019). The Five Factor Model of personality and social support: A metaanalysis. Journal of Research in Personality, 81, 38-46. https://doi.org/10.1016/j.jrp.2019.05.002

Barrera, M. (1986). Distinctions between social support concepts, measures, and models. American Journal of Community Psychology, 14(4), 413-445.

Bergeman, C. S., Plomin, R., Pedersen, N. L., McClearn, G. E., \& Nesselroade, J. R. (1990). Genetic and environmental influences on social support: The Swedish Adoption/Twin Study of Aging. Journal of Gerontology, 45(3), 101-106. https://doi.org/10.1093/geronj/45.3.P101

Berkman, L. F., Glass, T., Brissette, I., \& Seeman, T. E. (2000). From social integration to health: Durkheim in the new millennium. Social Science \& Medicine, 51(6), 843-857. https://doi.org/10.1016/S0277-9536(00)00065-4

Bernstein, M. J., \& Claypool, H. M. (2012). Not all social exclusions are created equal: Emotional distress following social exclusion is moderated by exclusion paradigm. Social Influence, 7(2), 113-130. doi: 10.1080/15534510.2012.664326 
RUNNING HEAD: PERSONALITY AND SOCIAL SUPPORT IN STRESS REACTIVITY

Bisconti, T. L., Bergeman, C. S., \& Boker, S. M. (2006). Social support as a predictor of variability: An examination of the adjustment trajectories of recent widows. Psychology and Aging, 21(3), 590- 599. https://doi.org/10.1037/0882-7974.21.3.590

Blackhart, G. C., Nelson, B. C., Knowles, M. L., \& Baumeister, R. F. (2009). Rejection elicits emotional reactions but neither causes immediate distress nor lowers self-esteem: A meta-analytic review of 192 studies on social exclusion. Personality and Social Psychology Review, 13(4), 269-309. doi: 10.1177/1088868309346065

Bolger, N., \& Amarel, D. (2007). Effects of social support visibility on adjustment to stress: experimental evidence. Journal of personality and social psychology, 92(3), 458-475.

Bolger, N., DeLongis, A., Kessler, R. C., \& Schilling, E. A. (1989). Effects of daily stress on negative mood. Journal of Personality and Social Psychology, 57(5), 808818. https://doi.org/10.1037/0022-3514.57.5.808

Bolger, N., \& Schilling, E. A. (1991). Personality and the problems of everyday life: The role of neuroticism in exposure and reactivity to daily stressors. Journal of Personality, 59(3), 355-386. doi: 10.1111/j.1467-6494.1991.tb00253.x

Bolger, N., \& Zuckerman, A. (1995). A framework for studying personality in the stress process. Journal of Personality and Social Psychology, 69(5), 890902. https://doi.org/10.1037/0022-3514.69.5.890

Bolger, N., Zuckerman, A., \& Kessler, R. C. (2000). Invisible support and adjustment to stress. Journal of Personality and Social Psychology, 79(6), 953961. https://doi.org/10.1037/0022-3514.79.6.953

Branje, S. J. T., van Lieshout, C. F. M., \& van Aken, M. A. G. (2004). Relations Between Big 
RUNNING HEAD: PERSONALITY AND SOCIAL SUPPORT IN STRESS REACTIVITY

Five Personality Characteristics and Perceived Support in Adolescents' Families. Journal of Personality and Social Psychology, 86(4), 615-628. https://doi.org/10.1037/00223514.86.4.615

Caspi, A., Bolger, N., \& Eckenrode, J. (1987). Linking person and context in the daily stress process. Journal of Personality and Social Psychology, 52(1), 184-195. doi: $10.1037 / / 0022-3514.52 .1 .184$

Cassel, J. (1976). The contribution of the social environment to host resistance: the Fourth Wade Hampton Frost Lecture. American Journal of Epidemiology, 104(2), 107-123.

Cobb, S. (1976). Social support as a moderator of life stress. Psychosomatic Medicine, 38(5), 300-314. https://doi.org/10.1097/00006842-197609000-00003

Cohen, S. (2004). Social relationships and health. American Psychologist, 59(8), 676-684.

Cohen, S., Gottlieb, B. H., \& Underwood, L. G. (2001). Social relationships and health: Challenges for measurement and intervention. Advances in Mind-Body Medicine, 17(2), $129-141$.

Cohen, S., Janicki-Deverts, D., Turner, R. B., \& Doyle, W. J. (2015). Does hugging provide stress-buffering social support? A study of susceptibility to upper respiratory infection and illness. Psychological Science, 26(2), 135-147.

Cohen, S., Mermelstein, R., Kamarck, T., \& Hoberman, H. M. (1985). Measuring the functional components of social support. In Social support: Theory, Research and Applications (pp. 73-94). Springer, Dordrecht.

Cohen, S., Underwood, L. G., \& Gottlieb, B. H. (Eds.). (2000). Social support measurement and intervention: A guide for health and social scientists. Oxford University Press.

Cohen, S., \& Wills, T. A. (1985). Stress, social support, and the buffering hypothesis. 
RUNNING HEAD: PERSONALITY AND SOCIAL SUPPORT IN STRESS REACTIVITY

Psychological Bulletin, 98(2), 310-357. https://doi.org/10.1037/0033-2909.98.2.310

Cook, P. F., McElwain, C. J., \& Bradley-Springer, L. A. (2016). Brief report on ecological momentary assessment: Everyday states predict HIV prevention behaviors. $B M C$ Research Notes, 9. https://doi.org/10.1186/s13104-015-1814-4

Coppersmith, D. D., Kleiman, E. M., Glenn, C. R., Millner, A. J., \& Nock, M. K. (2019). The dynamics of social support among suicide attempters: A smartphone-based daily diary study. Behaviour Research and Therapy, 120, 103348.

Costa Jr, P. T., \& McCrae, R. R. (2008). The Revised NEO Personality Inventory (NEO-PI-R). Sage Publications, Inc.

Cutrona, C. E. (1986). Behavioral manifestations of social support: A microanalytic investigation. Journal of Personality and Social Psychology, 51(1), 201208. https://doi.org/10.1037/0022-3514.51.1.201

David, J. P., \& Suls, J. (1999). Coping efforts in daily life: Role of Big Five traits and problem appraisals. Journal of Personality, 67(2), 265-294. https://doi.org/10.1111/14676494.00056

DeLongis, A., \& Holtzman, S. (2005). Coping in context: The role of stress, social support, and personality in coping. Journal of Personality, 73(6), 1633-1656. https://doi.org/10.1111/j.1467-6494.2005.00361.x

DeLongis, A., Folkman, S., \& Lazarus, R. S. (1988). The impact of daily stress on health and mood: Psychological and social resources as mediators. Journal of Personality and Social Psychology, 54(3), 486-495. https://doi.org/10.1037/0022-3514.54.3.486

Ditzen, B., \& Heinrichs, M. (2014). Psychobiology of social support: the social dimension of 
RUNNING HEAD: PERSONALITY AND SOCIAL SUPPORT IN STRESS REACTIVITY

stress buffering. Restorative Neurology and Neuroscience, 32(1), 149-162.

doi: $10.3233 / \mathrm{RNN}-139008$

Durkheim, É. (1897). Le suicide, étude de sociologie (Éd. 1897). Hachette Livre.

Eisenberger, N. I., Taylor, S. E., Gable, S. L., Hilmert, C. J., \& Lieberman, M. D. (2007). Neural pathways link social support to attenuated neuroendocrine stress

responses. Neuroimage, 35(4), 1601-1612.

https://doi.org/10.1016/j.neuroimage.2007.01.038

Feeney, B. C., \& Collins, N. L. (2015). A new look at social support: A theoretical perspective on thriving through relationships. Personality and Social Psychology Review, 19(2), 113147. doi: $10.1177 / 1088868314544222$

Feiler, D. C., \& Kleinbaum, A. M. (2015). Popularity, similarity, and the network extraversion bias. Psychological Science, 26(5), 593-603. https://doi.org/10.1177/0956797615569580

Finch, J. F., Okun, M. A., Pool, G. J., \& Ruehlman, L. S. (1999). A comparison of the influence of conflictual and supportive social interactions on psychological distress. Journal of Personality, 67(4), 581-621.

Folkman, S., \& Lazarus, R. S. (1984). Stress, Appraisal, and Coping (pp. 150-153). New York: Springer Publishing Company.

Gerber, J., \& Wheeler, L. (2009). On being rejected: A meta-analysis of experimental research on rejection. Perspectives on Psychological Science, 4(5), 468-488. https://doi.org/10.1111/j.1745-6924.2009.01158.x

Gerteis, A. K. S., \& Schwerdtfeger, A. R. (2016). When rumination counts: Perceived social support and heart rate variability in daily life. Psychophysiology, 53(7), 1034-1043. https://doi.org/10.1111/psyp.12652 
RUNNING HEAD: PERSONALITY AND SOCIAL SUPPORT IN STRESS REACTIVITY

Gleason, M. E., Iida, M., Bolger, N., \& Shrout, P. E. (2003). Daily supportive equity in close relationships. Personality and Social Psychology Bulletin, 29(8), 1036-1045.

Gleason, M. E. J., Iida, M., Shrout, P. E., \& Bolger, N. (2008). Receiving support as a mixed blessing: Evidence for dual effects of support on psychological outcomes. Journal of Personality and Social Psychology, 94(5), 824-838.

Gottlieb, B. H., \& Bergen, A. E. (2010). Social support concepts and measures. Journal of Psychosomatic Research, 69(5), 511-520.

https://doi.org/10.1016/j.jpsychores.2009.10.001

Grant, S., \& Langan-Fox, J. (2007). Personality and the occupational stressor-strain relationship: The role of the Big Five. Journal of Occupational Health Psychology, 12(1), 2033. https://doi.org/10.1037/1076-8998.12.1.20

Gunthert, K. C., Cohen, L. H., \& Armeli, S. (1999). The role of neuroticism in daily stress and coping. Journal of Personality and Social Psychology, 77(5), 1087-1100.

Hawkley, L. C., Preacher, K. J., \& Cacioppo, J. T. (2007). Multilevel modeling of social interactions and mood in lonely and socially connected individuals: The MacArthur social neuroscience studies.

Heller, K., Swindle, R. W., \& Dusenbury, L. (1986). Component social support processes: Comments and integration. Journal of Consulting and Clinical Psychology, 54(4), 466470. https://doi.org/10.1037/0022-006X.54.4.466

Holt-Lunstad, J., Smith, T. B., \& Layton, J. B. (2010). Social relationships and mortality risk: a meta-analytic review. PLoS med, 7(7), e1000316. https://doi.org/10.1371/journal.pmed.1000316

Hooker, K., Frazier, L. D., \& Monahan, D. J. (1994). Personality and coping among caregivers 
RUNNING HEAD: PERSONALITY AND SOCIAL SUPPORT IN STRESS REACTIVITY

of spouses with dementia. The Gerontologist, 34(3), 386-392.

https://doi.org/10.1093/geront/34.3.386

Howland, M., Armeli, S., Feinn, R., \& Tennen, H. (2017). Daily emotional stress reactivity in emerging adulthood: temporal stability and its predictors. Anxiety, Stress, \& Coping, 30(2), 121-132.

Kamarck, T. W., Li, X., Wright, A. G., Muldoon, M. F., \& Manuck, S. B. (2018). Ambulatory blood pressure reactivity as a moderator in the association between daily life psychosocial stress and carotid artery atherosclerosis. Psychosomatic Medicine, 80(8), 774-782. doi: 10.1097/PSY.0000000000000627

Kamarck, T. W., Muldoon, M. F., Shiffman, S., Sutton-Tyrrell, K., Gwaltney, C., \& Janicki, D. L. (2004). Experiences of demand and control in daily life as correlates of subclinical carotid atherosclerosis in a healthy older sample. Health Psychology, 23(1), 24-32. doi: $10.1037 / 0278-6133.23 .1 .24$

Karasek, R. A., Karasek, R., Gordon-Strachan, G., Pietrokovsky, C., Frese, M., Pieper, C. F., ... \& Schirer, D. (1985). Job Content Instrument: Questionnaire and user's guide.

Kawachi, I., \& Berkman, L. F. (2001). Social Ties and Mental Health. Journal of Urban Health, 78(3), 458-467.

Kiecolt-Glaser, J. K., \& Newton, T. L. (2001). Marriage and health: His and hers. Psychological Bulletin, 127(4), 472-503. https://doi.org/10.1037/0033-2909.127.4.472

Lakey, B., \& Drew, J. B. (1997). A social-cognitive perspective on social support. In Sourcebook of Social Support and Personality (pp. 107-140). Springer, Boston, MA.

Lakey, B., McCabe, K. M., Fisicaro, S. A., \& Drew, J. B. (1996). Environmental and personal 
RUNNING HEAD: PERSONALITY AND SOCIAL SUPPORT IN STRESS REACTIVITY

determinants of support perceptions: Three generalizability studies. Journal of Personality and Social Psychology, 70(6), 1270-1280. https://doi.org/10.1037/00223514.70.6.1270

Lakey, B., \& Orehek, E. (2011). Relational regulation theory: A new approach to explain the link between perceived social support and mental health. Psychological Review, 118(3), 482495.

Lara, M. E., Leader, J., \& Klein, D. N. (1997). The association between social support and course of depression: Is it confounded with personality? Journal of Abnormal Psychology, 106(3), 478-482. https://doi.org/10.1037/0021-843X.106.3.478

Liu, R. T., \& Alloy, L. B. (2010). Stress generation in depression: A systematic review of the empirical literature and recommendations for future study. Clinical Psychology Review, 30(5), 582-593.

Longua, J., DeHart, T., Tennen, H., \& Armeli, S. (2009). Personality moderates the interaction between positive and negative daily events predicting negative affect and stress. Journal of Research in Personality, 43(4), 547-555. doi: 10.1016/j.jrp.2009.02.006

Lutz, C. J., \& Lakey, B. (2001). How people make support judgments: Individual differences in the traits used to infer supportiveness in others. Journal of Personality and Social Psychology, 81(6), 1070-1079. https://doi.org/10.1037/0022-3514.81.6.1070

Lynam, D. R., Hoyle, R. H., \& Newman, J. P. (2006). The perils of partialling: Cautionary tales from aggression and psychopathy. Assessment, 13(3), 328-341. doi: $10.1177 / 1073191106290562$

Manuck, S. B., Marsland, A. L., Kaplan, J. R., \& Williams, J. K. (1995). The pathogenicity of 
RUNNING HEAD: PERSONALITY AND SOCIAL SUPPORT IN STRESS REACTIVITY

behavior and its neuroendocrine mediation: An example from coronary artery disease. Psychosomatic Medicine, 57(3), 275-283.

Maples, J., Miller, J. D., Hoffman, B. J., \& Johnson, S. L. (2014). A test of the empirical network surrounding affective instability and the degree to which it is independent from neuroticism. Personality Disorders: Theory, Research, and Treatment, 5(3), 268277. https://doi.org/10.1037/per0000019

Marco, C. A., \& Suls, J. (1993). Daily stress and the trajectory of mood: Spillover, response assimilation, contrast, and chronic negative affectivity. Journal of Personality and Social Psychology, 64(6), 1053-1063. https://doi.org/10.1037/0022-3514.64.6.1053

Mey, L. K., Chmitorz, A., Kurth, K., Wenzel, M., Kalisch, R., Tüscher, O., \& Kubiak, T. (2020). Increases of negative affect following daily hassles are not moderated by neuroticism: An ecological momentary assessment study. Stress and Health, $n / a(\mathrm{n} / \mathrm{a})$. https://doi.org/10.1002/smi.2964

Morelli, S. A., Leong, Y. C., Carlson, R. W., Kullar, M., \& Zaki, J. (2018). Neural detection of socially valued community members. Proceedings of the National Academy of Sciences, 115(32), 8149-8154. https://doi.org/10.1073/pnas.1712811115

Morelli, S. A., Ong, D. C., Makati, R., Jackson, M. O., \& Zaki, J. (2017). Empathy and wellbeing correlate with centrality in different social networks. Proceedings of the National Academy of Sciences, 114(37), 9843-9847. https://doi.org/10.1073/pnas.1702155114

Montoya, P., Larbig, W., Braun, C., Preissl, H., \& Birbaumer, N. (2004). Influence of social support and emotional context on pain processing and magnetic brain responses in fibromyalgia. Arthritis \& Rheumatism, 50(12), 4035-4044.

Mroczek, D. K., \& Almeida, D. M. (2004). The effect of daily stress, personality, and age on 
RUNNING HEAD: PERSONALITY AND SOCIAL SUPPORT IN STRESS REACTIVITY

daily negative affect. Journal of Personality, 72(2), 355-378.

Muthén, L. K., \& Muthén, B. O. (2019). Mplus: Statistical analyses with latent variables. User's guide version 8.3. Los Angeles, CA: Author.

Newsom, J. T., Nishishiba, M., Morgan, D. L., \& Rook, K. S. (2003). The relative importance of three domains of positive and negative social exchanges: a longitudinal model with comparable measures. Psychology and Aging, 18(4), 746-754. Doi: 10.1037/08827974.18.4.746

Newth, S., \& DeLongis, A. (2004). Individual differences, mood, and coping with chronic pain in rheumatoid arthritis: A daily process analysis. Psychology \& Health, 19(3), 283-305.

Nezlek, J. B., \& Allen, M. R. (2006). Social support as a moderator of day-to-day relationships between daily negative events and daily psychological well-being. European Journal of Personality: Published for the European Association of Personality Psychology, 20(1), 53-68. doi: 10.1002/per.566

Ozbay, F., Johnson, D. C., Dimoulas, E., Morgan III, C. A., Charney, D., \& Southwick, S. (2007). Social support and resilience to stress: from neurobiology to clinical practice. Psychiatry (Edgmont), 4(5), 35.

Paulhus, D. L., Robins, R. W., Trzesniewski, K. H., \& Tracy, J. L. (2004). Two replicable suppressor situations in personality research. Multivariate Behavioral Research, 39(2), 303-328. doi: 10.1207/s15327906mbr3902_7

Penley, J. A., \& Tomaka, J. (2002). Associations among the Big Five, emotional responses, and coping with acute stress. Personality and Individual Differences, 32(7), 1215-1228. https://doi.org/10.1016/S0191-8869(01)00087-3

Pierce, G. R., Lakey, B., Sarason, I. G., Sarason, B. R., \& Joseph, H. J. (1997). Personality and 
RUNNING HEAD: PERSONALITY AND SOCIAL SUPPORT IN STRESS REACTIVITY

social support processes. In Sourcebook of Social Support and Personality (pp. 3-18). Springer, Boston, MA.

Pietromonaco, P. R., \& Collins, N. L. (2017). Interpersonal mechanisms linking close relationships to health. American Psychologist, 72(6), 531-542. doi:

10.1037/amp0000129

Rueger, S. Y., Malecki, C. K., Pyun, Y., Aycock, C., \& Coyle, S. (2016). A meta-analytic review of the association between perceived social support and depression in childhood and adolescence. Psychological Bulletin, 142(10), 1017-1067. http://dx.doi.org/10.1037/bul0000058

Rohrer, J. M., \& Arslan, R. C. (2020, December 4). Precise Answers to Vague Questions: Issues With Interactions. https://doi.org/10.31234/osf.io/7fm2j

Rook, K. S. (1992). Detrimental aspects of social relationships: Taking stock of an emerging literature. In H. O. F. Veiel \& U. Baumann (Eds.), The series in clinical and community psychology. The meaning and measurement of social support (p. 157-169). Hemisphere Publishing Corp.

Schnall, P. L., Schwartz, J. E., Landsbergis, P. A., Warren, K., \& Pickering, T. G. (1992). Relation between job strain, alcohol, and ambulatory blood pressure. Hypertension, 19(5), 488-494.

Suls, J., Green, P., \& Hillis, S. (1998). Emotional reactivity to everyday problems, affective inertia, and neuroticism. Personality and Social Psychology Bulletin, 24(2), 127-136.

Suls, J., \& Martin, R. (2005). The daily life of the garden-variety neurotic: Reactivity, stressor exposure, mood spillover, and maladaptive coping. Journal of Personality, 73(6), 1485 1509. 10.1111/j.1467-6494.2005.00356.x 
RUNNING HEAD: PERSONALITY AND SOCIAL SUPPORT IN STRESS REACTIVITY

Swickert, R. J., Rosentreter, C. J., Hittner, J. B., \& Mushrush, J. E. (2002). Extraversion, social support processes, and stress. Personality and Individual Differences, 32(5), 877-891. https://doi.org/10.1016/S0191-8869(01)00093-9

Swickert, R., \& Owens, T. (2010). The interaction between neuroticism and gender influences the perceived availability of social support. Personality and Individual Differences, 48(4), 385-390. https://doi.org/10.1016/S0191-8869(01)00093-9

Trull, T. J., \& Ebner-Priemer, U. (2013). Ambulatory assessment. Annual Review of Clinical Psychology, 9, 151-176.

Vollrath, M. (2001). Personality and stress. Scandinavian Journal of Psychology, 42(4), 335-347. https://doi.org/10.1111/1467-9450.00245

Watson, D., Clark, L. A., Chmielewski, M., \& Kotov, R. (2013). The value of suppressor effects in explicating the construct validity of symptom measures. Psychological Assessment, 25(3), 929-941. https://doi.org/10.1037/a0032781

Williams, W. C., Morelli, S. A., Ong, D. C., \& Zaki, J. (2018). Interpersonal emotion regulation: Implications for affiliation, perceived support, relationships, and well-being. Journal of Personality and Social Psychology, 115(2), 224-

254. https://doi.org/10.1037/pspi0000132

Wills, T. A., \& Shinar, O. (2000). Measuring perceived and received social support. In S. Cohen, L. G. Underwood, \& B. H. Gottlieb (Eds.), Social support measurement and intervention: A guide for health and social scientists (p. 86-135). Oxford University Press.

Wright, A.G.C. (2011). Quantitative and qualitative distinctions in personality disorder. Journal of Personality Assessment, 93(4), 370-379. 
RUNNING HEAD: PERSONALITY AND SOCIAL SUPPORT IN STRESS REACTIVITY

Wright, A.G.C. (2014). Integrating trait and process based conceptualizations of pathological narcissism in the DSM-5 era. In A. Besser (Ed.) Handbook of psychology of narcissism: Diverse perspectives (pp. 153-174). Hauppauge, NY: Nova Science Publishers.

Wright, A. G., Aslinger, E. N., Bellamy, B., Edershile, E. A., \& Woods, W. C. (2019). Daily Stress and Hassles. In The Oxford Handbook of Stress and Mental Health (p. 27). Oxford University Press.

Zinbarg, R. E., Revelle, W., Yovel, I., \& Li, W. (2005). Cronbach's $\alpha$, Revelle's $\beta$, and McDonald's $\omega \mathrm{H}$ : Their relations with each other and two alternative conceptualizations of reliability. Psychometrika, 70(1), 123-133. doi: 10.1007/s11336-003-0974-7 
RUNNING HEAD: PERSONALITY AND SOCIAL SUPPORT IN STRESS REACTIVITY

\section{Acknowledgements}

We are grateful to the participants who took part in this study and to Barbara Anderson, the project coordinator of the study, as well as the other staff and students associated with the SHINE study, who made this work possible. 
RUNNING HEAD: PERSONALITY AND SOCIAL SUPPORT IN STRESS REACTIVITY

Table 1

Descriptive Statistics of key Study Variables.

\begin{tabular}{|c|c|c|c|c|c|}
\hline & $n$ & Mean $(S D)$ & range & $\alpha$ & CI* \\
\hline Neuroticism & 372 & $27.6(7.08)$ & $13-50$ & .80 & $.77 ; .82$ \\
\hline Extraversion & 372 & $42.01(6.83)$ & $25-60$ & .82 & $.78 ; .84$ \\
\hline Positive Social Exchanges & 390 & $16.32(7.94)$ & $0-40$ & .90 & $.89 ; .92$ \\
\hline Information & 390 & $4.46(2.5)$ & $0-12$ & .86 & $.83 ; .89$ \\
\hline Instrumental & 390 & $5.17(2.68)$ & $0-12$ & .84 & $.82 ; .87$ \\
\hline Companionship & 390 & $3.18(2.36)$ & $0-12$ & .82 & $.77 ; .86$ \\
\hline Emotional Support & 390 & $3.51(2.21)$ & $0-10$ & .74 & $.69 ; .78$ \\
\hline Perceived Social Support & 381 & $40.81(6.1)$ & $17-48$ & .86 & $.84 ; .89$ \\
\hline Appraisal & 381 & $14.18(2.38)$ & $5-16$ & .79 & $.74 ; .84$ \\
\hline Belonging & 381 & $12.76(2.75)$ & $4-16$ & .80 & $.76 ; .84$ \\
\hline \multirow[t]{2}{*}{ Tangible } & 381 & $13.87(2.23)$ & $4-16$ & .69 & $.62 ; .75$ \\
\hline & & & & $\omega_{\text {BETWEEN }}$ & WWITHIN \\
\hline \multirow{2}{*}{ perceived stress } & $11275 /$ & $.99(1.87) /$ & \multirow{2}{*}{$0-10$} & \multirow{2}{*}{--} & \multirow{2}{*}{--} \\
\hline & 19165 & $1.37(1.89)$ & & & \\
\hline task demand & 19165 & $2.72(2.61)$ & $0-9$ & .92 & .86 \\
\hline social conflict & 11275 & $2.67(2.9)$ & $0-9$ & .95 & .82 \\
\hline
\end{tabular}

Note. *adjusted bootstrap percentile (BCa) confidence intervals (CIs). Values left of the backslash refer to social conflict and values right of the backlash to those derived from task demand analyses. We extracted only responses pertaining to interactions reported to be occurring at the time of or within the 10-minute period preceding the ED assessment, which resulted in fewer numbers of observations for social conflict compared to task demand. 
RUNNING HEAD: PERSONALITY AND SOCIAL SUPPORT IN STRESS REACTIVITY

\section{Table 2}

Key Standardized Coefficients from Focal Multilevel Models Predicting Perceived Stress from

Stressor Exposure and Simple vs. Multiple Prediction Model by Personality and Social Support.

\begin{tabular}{|c|c|c|}
\hline \multirow[b]{2}{*}{ Variable } & Task Demand & Social Conflict \\
\hline & $\beta[95 \% \mathrm{CI}]$ & $\beta[95 \% \mathrm{CI}]$ \\
\hline \multicolumn{3}{|l|}{ Neuroticism (N) } \\
\hline Stress $\rightarrow$ Stressor* & $.23[.21 ; .24]$ & $.30[.24 ; .33]$ \\
\hline $\mathrm{N} \rightarrow$ Stressor & $.06[-.02 ; .13]$ & $.23[.16 ; .31]$ \\
\hline $\mathrm{N} \rightarrow$ Stress & $.33[.26 ; .40]$ & $.34[.27 ; .41]$ \\
\hline $\mathrm{N} \rightarrow$ Reactivity & $.19[.09 ; .27]$ & $.12[.02 ; .20]$ \\
\hline \multicolumn{3}{|l|}{ Extraversion (E) } \\
\hline Stress $\rightarrow$ Stressor* & $.23[.21 ; .24]$ & $.31[.24 ; .33]$ \\
\hline $\mathrm{E} \rightarrow$ Stressor & $.09[.01 ; .16]$ & $-.08[-.15 ; .02]$ \\
\hline $\mathrm{E} \rightarrow$ Stress & $-.07[-.15 ; .00]$ & $-.07[-.14 ; .02]$ \\
\hline $\mathrm{E} \rightarrow$ Reactivity & $-.06[-.15 ; .02]$ & $-.09[-.18 ; .00]$ \\
\hline \multicolumn{3}{|l|}{ Perceived Social Support (PSS) } \\
\hline Stress $\rightarrow$ Stressor* & $.22[.20 ; .24]$ & $.31[.28 ; .33]$ \\
\hline PSS $\rightarrow$ Stressor & $.05[-.01 ; .14]$ & $-.16[-.23 ;-.08]$ \\
\hline PSS $\rightarrow$ Stress & $-.20[-.27 ;-.12]$ & $-.20[-.27 ;-.14]$ \\
\hline PSS $\rightarrow$ Reactivity & $-.13[-.20 ;-.04]$ & $-.00[-.09 ; .10]$ \\
\hline \multicolumn{3}{|l|}{ Received Social Support (RSS) } \\
\hline Stress $\rightarrow$ Stressor* & $.22[.21 ; .24]$ & $.30[.28 ; .32]$ \\
\hline RSS $\rightarrow$ Stressor & $-.02[-.10 ; .06]$ & $.07[-.00 ; .13]$ \\
\hline $\mathrm{RSS} \rightarrow$ Stress & $.06[-.01 ; .12]$ & $.06[-.00 ; .11]$ \\
\hline $\mathrm{RSS} \rightarrow$ Reactivity & $-.02[-.10 ; .06]$ & $-.04[-.14 ; .06]$ \\
\hline
\end{tabular}

Note. Person-level $N=370$; momentary-level $N_{T S}=19165, N_{S C}=11275 ; *=$ within-level standardized estimates averaged over clusters; Reactivity represents the within person association between reported stressors and perceived stress. $\mathrm{X} \rightarrow$ Reactivity denotes that as an individual's $\mathrm{X}$ trait level increases, so does the strength of association between a reported stressor and perceived stress (i.e., cross-level interaction). PSS = perceived social support; RSS = received social support; All models controlled for age, gender, race and education. These coefficients for covariates are not presented for parsimony. Boldfaced values are significant at a 95\% CI. 
RUNNING HEAD: PERSONALITY AND SOCIAL SUPPORT IN STRESS REACTIVITY

\section{Table 3}

Key Standardized Coefficients from Focal Multilevel Models Predicting Perceived Stress from Stressor Exposure and Multivariable Prediction by Personality and Social Support.

\begin{tabular}{|c|c|c|}
\hline & Task Demand & Social Conflict \\
\hline Variable & $\beta[95 \% \mathrm{CI}]$ & $\beta[95 \% \mathrm{CI}]$ \\
\hline Stress $\rightarrow$ Stressor* & $.22[.21 ; .24]$ & $.31[.24 ; .32]$ \\
\hline $\mathrm{N} \rightarrow$ Stressor & $.12[.05 ; .20]$ & $.20[.12 ; .26]$ \\
\hline $\mathrm{E} \rightarrow$ Stressor & $.11[.03 ; .18]$ & $.03[-.06 ; .11]$ \\
\hline PSS $\rightarrow$ Stressor & $.07[-.01 ; .16]$ & $-.10[-.18 ;-.02]$ \\
\hline $\mathrm{RSS} \rightarrow$ Stressor & $.03[-.05 ; .12]$ & $.01[-.07 ; .11]$ \\
\hline $\mathrm{N} \rightarrow$ Stress & $.33[.22 ; .38]$ & $.32[.22 ; .39]$ \\
\hline $\mathrm{E} \rightarrow$ Stress & $.09[.01 ; .17]$ & .09 [.01; .17] \\
\hline PSS $\rightarrow$ Stress & $-.14[-.24 ;-.06]$ & $-.15[-.24 ;-.06]$ \\
\hline RSS $\rightarrow$ Stress & $-.02[-.09 ; .04]$ & $-.01[-.08 ; .05]$ \\
\hline $\mathrm{N} \rightarrow$ Reactivity & $.18[.07 ; .28]$ & $.11[-.02 ; .21]$ \\
\hline $\mathrm{E} \rightarrow$ Reactivity & $.01[-.08 ; .10]$ & $-.11[-.21 ; .03]$ \\
\hline $\mathrm{PSS} \rightarrow$ Reactivity & $-.08[-.19 ; .01]$ & $.05[-.07 ; .14]$ \\
\hline RSS $\rightarrow$ Reactivity & $-.07[-.17 ; .01]$ & $-.04[-.19 ; .07]$ \\
\hline
\end{tabular}

Note. Person-level $N=370$; momentary-level $N_{T S}=19165, N_{S C}=11275 ; *$ = within-level standardized estimates averaged over clusters; Reactivity represents the within person association between reported stressors and perceived stress. $\mathrm{X} \rightarrow$ Reactivity denotes that as an individual's $\mathrm{X}$ trait level increases, so does the strength of association between a reported stressor and perceived stress (i.e., cross-level interaction). PSS = perceived social support; RSS = received social support; All models controlled for age, gender, race and education. These coefficients for covariates are not presented for parsimony. Boldfaced values are significant at a 95\% CI. 


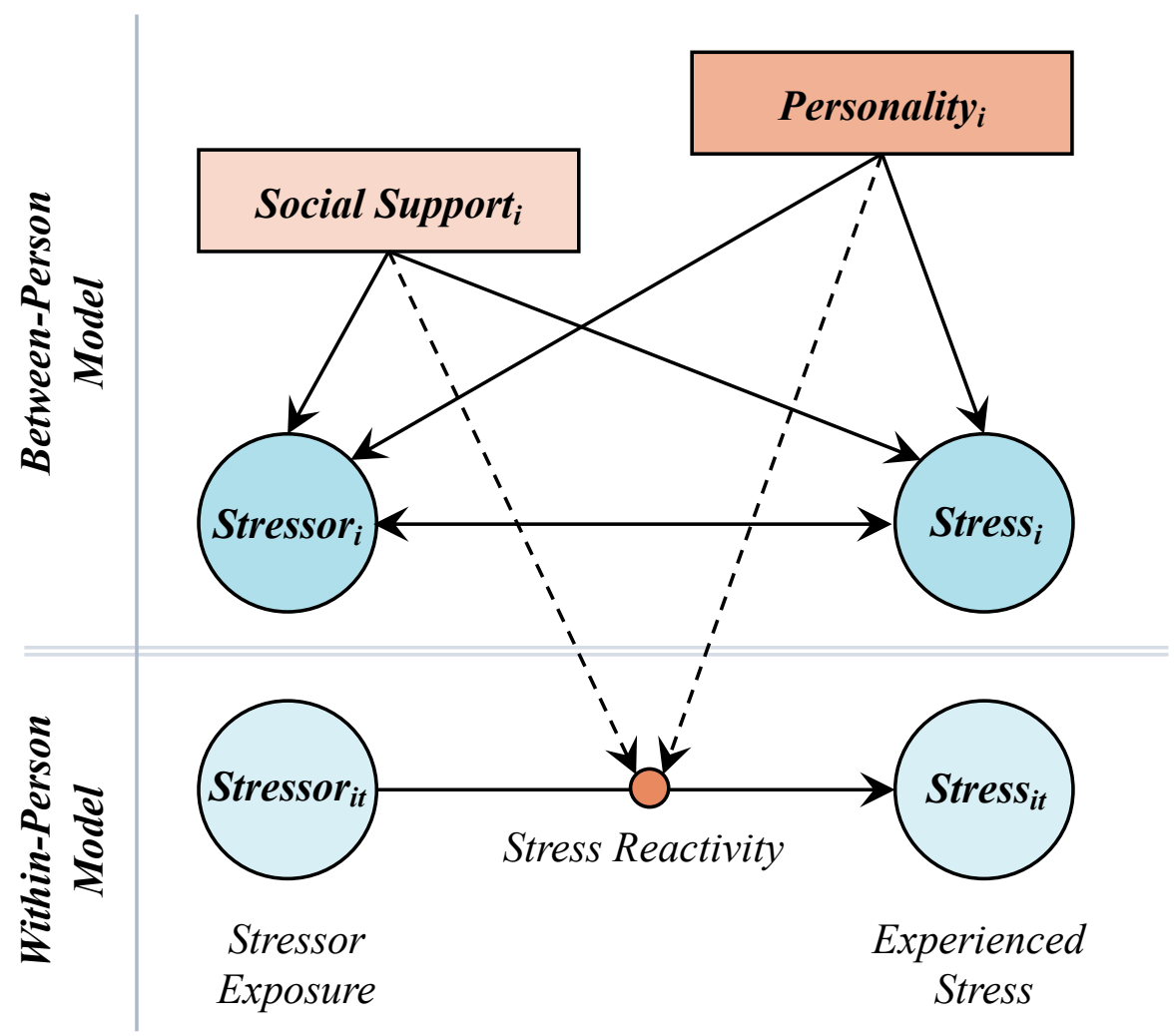

Figure 1. Model used for all analyses including decomposition of observed momentary variables into between- (subscript i) and within-person (subscript t) variance. All models controlled for age, gender, race (i.e., white/non-white) and education (4-point scale representing meaningful social increments: high school, some college or associates, BA/BS, post-BA degree). Coefficients for covariates are not presented for parsimony. Stressors were operationalized either as task demand or social conflict, and models were run separately for each scale. Single headed arrows indicate regression paths; double headed arrows indicate correlations. Filled in dot represents random effects. Reactivity represents the within person association between reported stressors and perceived stress. Dashed arrows denote cross-level interactions: i.e., as an individual's personality, perceived or received social support between-person level variable changes, so does the strength of the within-person association between stressor exposure and perceived stress. 